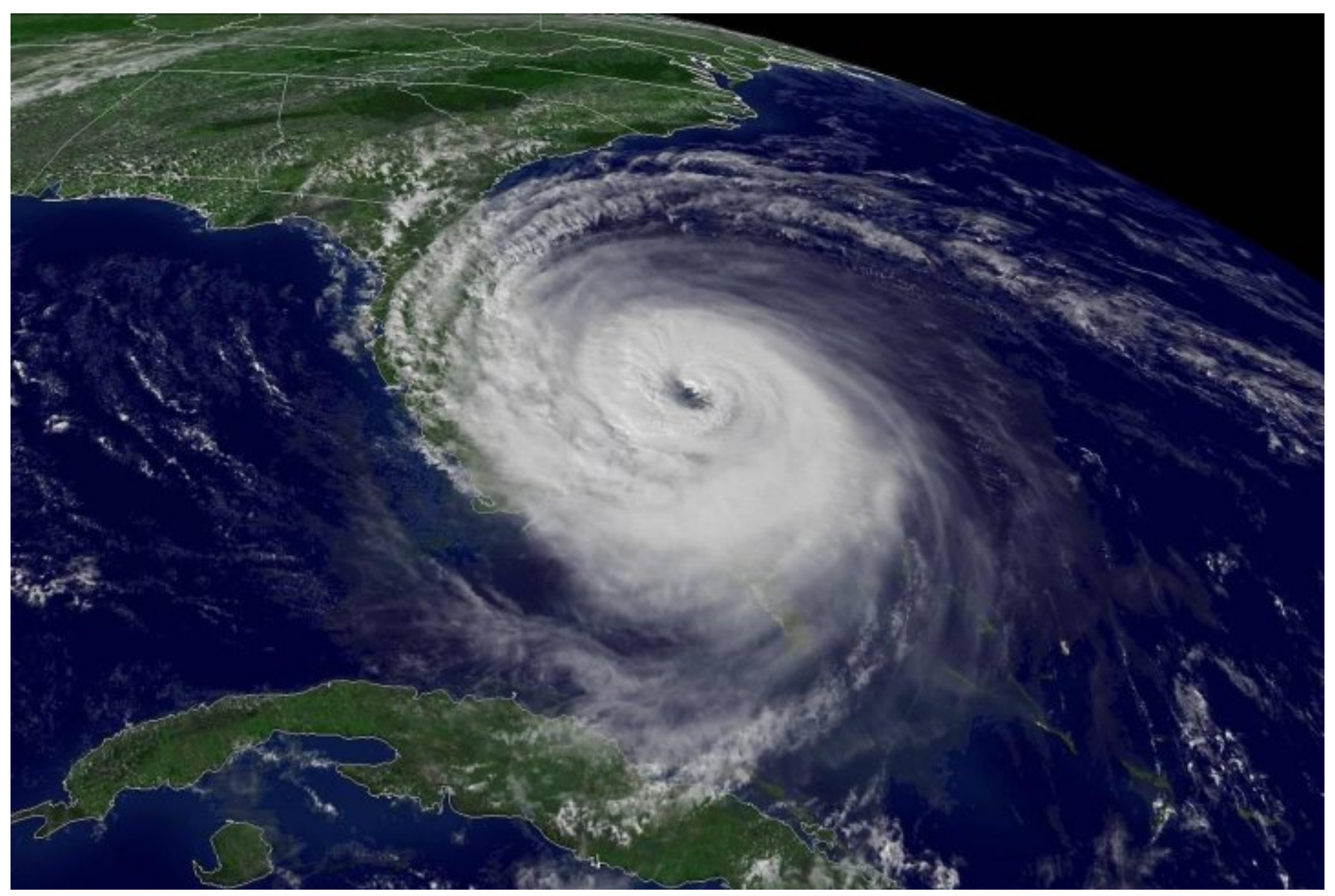

Chapter 1

\title{
Cleaning Up After a Hurricane - Safety Comes First!
}

Astrid Delgado, Eliana Kampf, Carol Lehtola, Traci Partin, Mary Duryea, and Edward Gilman
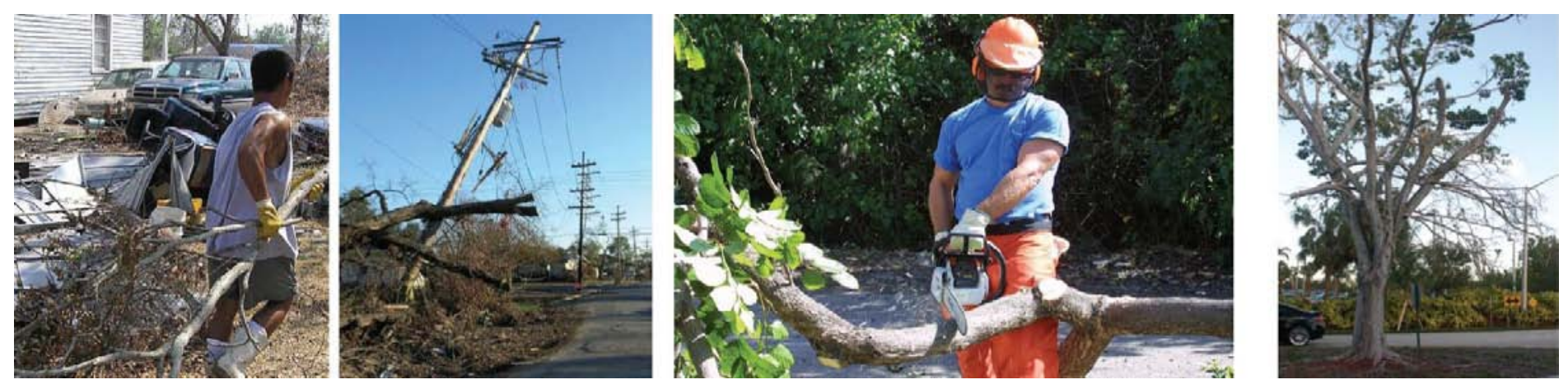

Urban Forest Hurricane Recovery Program http://treesandhurricanes.ifas.ufl.edu 


\section{Cleaning Up After a Hurricane - Salioty Comes First!}

Most injuries and deaths in a natural disaster occur during cleanup. Safety must be the first concern.

\section{General Safety Tips}

- Do not work alone.

- Keep a well stocked first-aid kit nearby and learn how to use it.

- Avoid overexertion - this is the most common cause for injury. Avoid lifting over 50 pounds. Remember to lift with the legs and not the back.

\section{Chain Saw Safety}

Chain saws are considered the most dangerous hand tool available. The risk of injury increases during hurricane cleanup when chain saws are widely used to remove trees and branches. Use these guidelines to avoid injuries:

- Follow manual instructions carefully to ensure safe operation and proper equipment maintenance.

- Wear the appropriate personal protective equipment.
- Keep both hands on the handles. Many chain saw injuries affect the hands and are the result of using the saw with just one hand.

- Cut at waist level or below. Chain saw injuries to the head often result from making overhead cuts.

- Take extra care when cutting limbs that are bent, twisted, or caught under another object. They may snap back and hit you or pinch the saw.

- Take the time to do the job right. Most injuries affect the legs and feet and are the result of aggressive or careless cutting. Take breaks when needed, because most injuries occur when workers are fatigued.

- Shut off equipment when fueling the saw or carrying it a distance of more than 100 feet, or through slippery areas or heavy brush.

- Be sure the chain saw operator is aware of your presence before you approach. Chain saw operators often cannot see or hear the approach of other people.

- Do not cut with the upper tip of the chain saw to avoid kickback.

1. This document is FOR 115, one of the Urban Forest Hurricane Recovery Program series of the School of Forest Resources and Conservation and the Environmental Horticulture Department, Florida Cooperative Extension Service, Institute of Food and Agricultural Sciences, University of Florida. Original publication date January 2007. Visit the EDIS Web Site at http://edis.ifas.ufl.edu and http://treesandhurricanes.ifas.ufl.edu.

2. Astrid Delgado, Urban Forester Landscaping Specialist, School of Forest Resources and Conservation; Eliana Kampf, Urban Forester, School of Forest Resources and Conservation; Carol Lehtola, Associate Professor and State Extension Agricultural Safety Specialist, Department of Agricultural and Biological Engineering; Traci Partin, Horticultural Information Specialist, Department of Environmental Horticulture; Mary Duryea, Professor, School of Forest Resources and Conservation and Associate Dean for Research, IFAS; Edward Gilman, Professor, Department of Environmental Horticulture; University of Florida, Institute of Food and Agricultural Sciences, Gainesville, FL 32611

The Institute of Food and Agricultural Sciences (IFAS) is an Equal Employment Opportunity - Affirmative Action Employer authorized to provide research, educational information and other services only to individuals and institutions that function without regard to race, creed, color, religion, age, disability, sex, sexual orientation, marital status, national origin, political opinions or affiliations. For information on obtaining other extension publications, contact your county Cooperative Extension Service office. Florida Cooperative Extension Service / Institute of Food and Agricultural Sciences / University of Florida / Larry R. Arrington, Dean. 


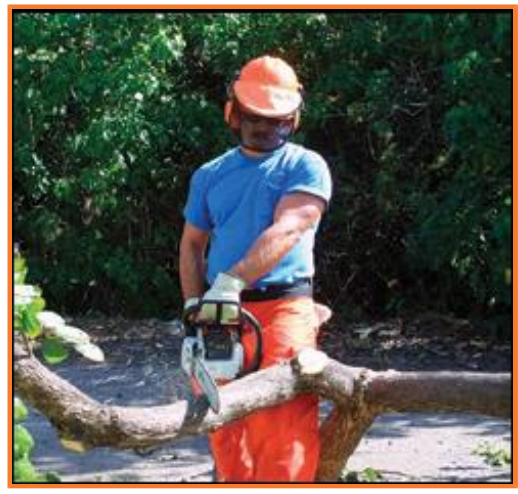

Figure 1. Cut at waist level or below. ๑ 2003 HOT PIXEL PRESS/ARBOR GLOBAL LLC

Kickback occurs when the upper tip of the guide bar contacts an object and causes the saw to come straight back at the operator. Kickback happens so fast that there is no time for reaction.

How to prevent: Cut with the part of the bar closest to the engine. Watch where the tip is at all times do not let it contact the ground or other branches.

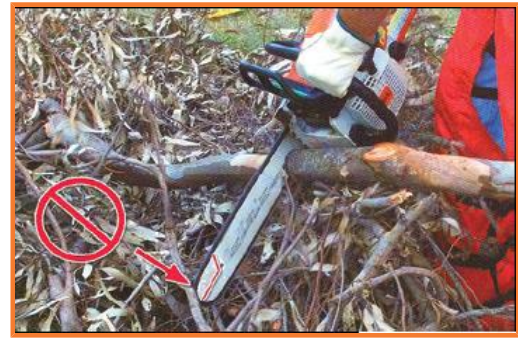

Figure 2. Do not cut with the upper tip!

๑) 2003 HOT PIXEL PRESS/ARBOR GLOBAL LLC

\section{Create a Safe Work Zone}

- Survey the site to identify potential hazards and discuss where there is potential for injuries. Agree on communication signals before you start to work.

- Set a perimeter around the work area that is two times the height of the tree. More distance is required when felling trees or dropping limbs.

- Mark the area with tape or cones and keep non-workers safely outside this area.

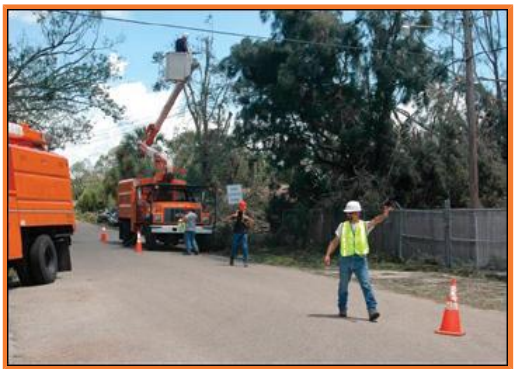

Figure 3. Appoint a flagger or use barricades and warning signs to control traffic or onlookers.

๑ 2003 HOT PIXEL PRESS/ARBOR GLOBAL LLC

\section{Personal Protective Equipment}

The correct use of the personal protective equipment reduces the likelihood of injury by covering key areas of the body.

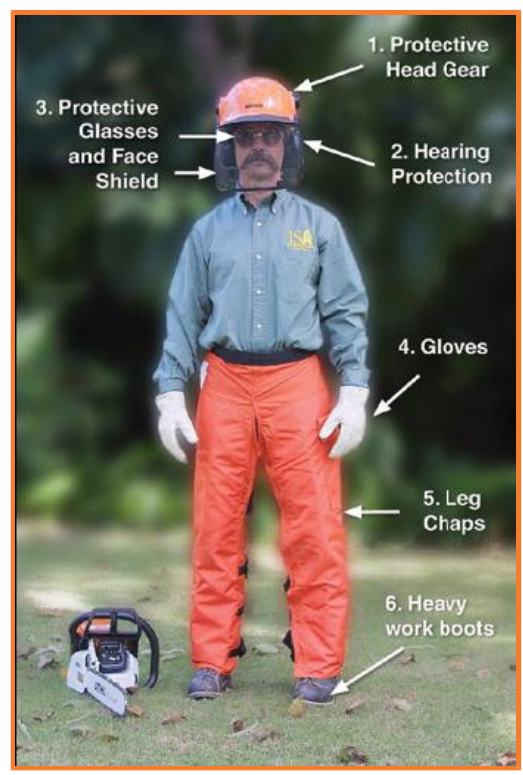

Figure 4. All tree workers should wear the appropriate clothing and footwear.

๑) 2003 HOT PIXEL PRESS/ARBOR GLOBAL LLC

\section{Storm damage cleanup is extremely dangerous even for professionals!}

More safety information is available at the Florida AgSafe web site www.flagsafe.ufl.edu 